\title{
APROXIMACIONES A LA NOVELA ESPAÑOLA DEL SIGLO XX
}

Luis Goytisolo

1

Al tener el honor de ser invitado a pronunciar estas palabras aquí y ahora por el señor Hideo Hotta, presidente de la Asociación Japonesa de Hispanistas, la primera idea que vino a mi mente fue la de hablar de pintura, de la pintura española contemporánea, Picasso, Juan Gris, Miró, Dalí, Antonio López, Miquel Barceló. La razón de esa primera idea no sabría decirla. Como bien sabemos, rastrear nuestras ideas, seguir el hilo que conduce hasta su origen nada tiene de sencillo. Por una parte, me gusta la pintura y esa afición está presente, aunque sólo sea tangencialmente, en alguna de mis obras. Por otra, la cultura japonesa y la española tienen en común el hecho de que la pintura y la creación literaria son precisamente sus dos pilares principales. Conozco muy directamente el interés que existe en Japón hacia la pintura europea; recuerdo que, cuando vivía en las proximidades del Museo del Prado me cruzaba constantemente con grupos de turistas japoneses que entraban y salían por la puerta de Goya. También recuerdo, hará unos 18 o 19 años, haber visitado diversos museos en Tokio guiado por Carlos Kanki, amigo que fue también del profesor Norio Shimizu. Me llamó especialmente la atención una observación suya relativa al escaso aprecio, en Japón, hacia determinado tipo de pintura religiosa - la relacionada con la Cruz o con los mártires - por considerarla de una desagradable crueldad. Habituado desde niño a la presencia de esas imágenes, sólo entonces se me ocurrió pensar que en realidad a mí me pasaba algo muy parecido. Aparte de unas pocas obras maestras (El Cristo de Van Eyck, el de Velázquez, "Cristo entre los fariseos", de El Bosco), este tipo de pintura religiosa me ha parecido siempre desagradable cuando no, además relamida y hasta cursi. Es decir: un tipo de arte que obedece a determinadas creencias o a determinados valores tradicionales antes que a un verdadero impulso artístico.

En el terreno de la creación literaria las cosas siempre han ido por otro lado, ya que las literaturas en lenguas romances se desarrollaron llevadas por el deseo de afirmarse al margen de los textos piadosos, algo que la pintura sólo consiguió a partir del 
Renacimiento. Si algún riesgo ha corrido la creación literaria ha sido más bien el de convertirse en vehículo de ideologías en los siglos XIX y XX y, más recientemente, en ponerse al servicio del mercado, en convertirse en un producto más de oferta. Pero estamos hablando ya de algo - la creación literaria - que por su propia naturaleza es menos conocido en Japón que las artes plásticas: una novela, un libro de poesía no son fotografiables como pueda serlo una pintura. No se trata ya de que la literatura sea un arte del tiempo mientras que la pintura lo es del espacio, sino de que una obra literaria precisará ante todo de una traducción. Aquí, en el seno de esta Asociación, no es un problema; fuera de aquí, lo es. Y a ese problema habría que añadir el que surgió, hablando con Carlos Kanki, acerca de determinada pintura religiosa. Es decir: que la literatura de la que estamos hablando careciese de interés para el público lector del Japón, no por su carácter religioso en este caso, sino por localista. Pero estoy convencido de que la verdadera creación literaria puede ser comprendida con independencia del tiempo y el lugar en que haya sido escrita, trátese de Góngora o de Basho, de Homero o del anónimo autor del Génesis.

De forma imperceptible, hemos pasado de la pintura a la literatura, y mi primitiva idea de hablarles de la pintura contemporánea española ha derivado en una disquisición que llega hasta la novela contemporánea. Un tema que tiene la ventaja añadida de referirse a un periodo coetáneo de esta Asociación, ya que coincide casi exactamente con la segunda mitad del siglo XX. Lo único embarazoso será que, en el curso de estas aproximaciones que me propongo desarrollar, me ha de resultar inevitable hablar, entre otros, de mí mismo. Pero, aparte de que posiblemente algo de eso se esperaba de mí, me comprometo a hablar de Luis Goytisolo con el máximo distanciamiento, como de alguien que poco o nada tuviese que ver conmigo.

La creación literaria española contemporánea, si la comparamos con la de los vecinos países europeos, tiene sin duda rasgos atípicos. La razón de esa singularidad hay que buscarla, creo yo, en el hecho de que España no tomó parte en ninguna de las dos guerras mundiales que sacudieron el Continente, lo que dio lugar a una diferente experiencia colectiva que también puede ser entendida como desfase. Así, por ejemplo, en el terreno de la poesía, la Generación del 27 , con todo y ser verdaderamente brillante, tiene poco que ver con lo que se escribía en el resto de Europa, dominada por los diversos ismos entonces en boga. Si acaso, cabría establecer similitudes con determinados poetas ingleses (Auden, Spender) cuyo país tampoco sufrió directamente los efectos de la guerra. La Segunda Guerra Mundial que, como sabemos, tuvo su prólogo en España en 
forma de guerra civil, contribuyó a perpetuar esa diferenciación ya que en España se mantuvo un sistema político que en el resto de los países había desaparecido en 1945. Lo cual explica que, el terreno de la narrativa, el modelo decimonónico se mantuviera vigente hasta mediados del siglo XX. Tal es el caso de Baroja, evidentemente, pero también el de Valle Inclán, y el de escritores que empezaron a escribir en la inmediata post-guerra, como el Cela de "La familia de Pascual Duarte" o la Carmen Laforet de "Nada", sin duda la novela más interesante de ese periodo.

Puestos a poner una fecha y a fijar un hito, yo diría que la novela española del siglo XX empieza en 1955 con la publicación de "El Jarama", de Rafael Sánchez Ferlosio. Una realidad que ha terminado por imponerse en la critica más lúcida: sólo a partir de "El Jarama", la novela española empieza a ser equiparable a la que se escribía treinta años antes en el resto de Europa. Un fenómeno, así pues, tardío, pero no por ello falto de interés, toda vez que propició el que en España siguieran apareciendo obras interesantes cuando en otros países empezaba ya a percibirse el vacío que en todas partes ha precedido a la irrupción de las novelas producidas en función del Mercado.

La novedad de "El Jarama" reside tanto en la estructura de la obra como en el propio lenguaje. Se trata de un lenguaje desprovisto de toda adherencia literaria anterior y de toda retórica, un idioma coloquial de doble signo: el de los asiduos a una venta situada a orillas del Jarama, el rico idioma de la gente de campo, y la jerga urbana de un grupo de excursionistas madrileños que acude a esa venta a pasar el domingo. La acción, casi nula, se desarrolla fundamentalmente a modo de precisiones relativas al constante dialogar de los personajes. La insatisfacción, o mejor, la frustración que traslucen esos diálogos termina por imponerse al significado estricto de las palabras. Pero, hagámonos aunque sólo sea una idea de todo ello a través del propio texto, del fragmento inaugural de la obra.

\section{(Cita 1)}

- ¿Me dejas que descorra la cortina?

Siempre estaba sentado de la misma manera: su espalda contra lo oscuro de la pared del fondo; su cara contra la puerta, hacia la luz. El mostrador corría a su izquierda, paralelo a su mirada. Colocaba la silla de lado, de modo que el respaldo de ésta le sostribase el brazo derecho, mientras ponía el izquierdo sobre el mostrador. Así que se encajaba como en una hornacina, parapetando su cuerpo por tres lados; y por el cuarto quería tener luz. Por el frente quería tener abierto el camino de la cara y no soportaba que la cortina le cortase la vista hacia afuera de la puerta.

- ¿Me dejas que descorra la cortina? 
El ventero asentía con la cabeza. Era un lienzo pesado, de tela de costales.

Pronto le conocieron la manía y en cuanto se hubo sentado una mañana, como siempre, en su rincón, fue el mismo ventero quien aportó la cortina, sin que él se lo hubiese pedido. Lo hizo ceremonioso, con un gesto alusivo, y el otro se ofendió:

- Si te molesta que abra la cortina, podías haberlo dicho, y me largo a beber en otra parte. Pero ese retintín que te manejas, no es manera de decirme las cosas.

-Pero hombre, Lucio, ¿ni una broma tan chica se te puede gustar? No me molesta, hombre; no es más que por las moscas, ahora en el verano; pero me da lo mismo, si estás a gusto así. Sólo que me hace gracia el capricho que tienes con mirar para afuera. ¿No estás harto de verlo? Siempre ese mismo árbol y ese cacho camino y esa tapia.

“¿Me dejas que descorra la cortina?” Así comienza el texto del relato propiamente dicho, tras un párrafo en el que se describe brevemente el curso del río Jarama desde un punto de vista geográfico. Me resulta llamativo que ningún crítico, que yo sepa, haya establecido un paralelo entre esa cortina que se descorre como un telón y el introibo ad altare Dei, la frase que a semejanza de lo que sucedía en la misa latina, la misa pre-conciliar, puesta en boca de Buck Mulligan, parece abrir la larga jornada dublinesa del "Ulises", de Joyce. Pues, por lo demás, las vicisitudes de bañistas y lugareños durante un domingo de verano junto al Jarama se prolongan exactamente durante 16 horas, mientras que las andanzas cruzadas de S. Dedalus y de L. Bloom, un 16 de junio en Dublín, abarcan unas 18 , el número de capítulos que tiene la obra. Y si por las calles de Dublín aparece reiteradamente un desconocido, "el hombre de la gabardina marrón", que termina siendo mister McIntosh, a orillas del Jarama aparecerá una y otra vez "el hombre de los zapatos blancos", al final unas simples iniciales minúsculas, ZB.

La influencia del "Ulises" en "Tiempo de silencio", de Luis Martín Santos, está en cambio ampliamente aceptada. Parece ser que anteriormente había escrito una novela a la manera de Hemingway, que Martín Santos prefirió no publicar, con lo que "Tiempo de silencio" vendría a ser una novela "a la manera de Joyce", es decir, un ejercicio de estilo -en este caso, más aceptable para su autor- en la búsqueda de su propia voz. El deambular de Pedro por el Madrid de 1949, tiene un estrecho paralelo con el del Bloom y Dedalus por el Dublín de 1904: encuentros fortuitos, bares, mundillo intelectual, visita a un prostíbulo... Y también - a diferencia de "El Jarama"- el amplio registro de tonos y estilos que se suceden. Su influencia en otros autores - al igual que la de Sánchez Ferlosio- fue grande. Se señala, en este sentido, la que pudo tener en la trilogía de Juan 
Goytisolo, no como modelo imitado, por supuesto, sino como texto inspirador de nuevos puntos de partida. También se ha señalado la posible relación entre el Madrid evocado por Martín Santos y la Barcelona que aparece en mi novela, "Antagonía”. Debo decir a este respecto, que no veo que tal relación exista, ya que la intención del autor es, en uno y otro caso, contrapuesta: el Madrid de Luis Martín Santos tiene algo de insecto clavado con un alfiler por un entomólogo, mientras que la Barcelona de "Antagonía" es más bien la ciudad ideal, una ciudad existente antes en la mente de sus habitantes que en la realidad. Por lo demás, Luis Martín Santos cree que la función de la novela — de su novela, de toda novela- es cambiar la sociedad. Escuchémosle.

\section{(Cita 2)}

Hay ciudades tan descabaladas, tan faltas de sustancia histórica, tan traídas y llevadas por gobernantes arbitrarios, tan caprichosamente edificadas en desiertos, tan parcamente pobladas por una continuidad aprehensible de familias, tan lejanas de un mar o de un río, tan ostentosas en el reparto de su menguada pobreza, tan favorecidas por un cielo espléndido que hace olvidar casi todos sus defectos, tan ingenuamente contentas de sí mismas al modo de las mozas quinceñas, tan globalmente adquiridas para el prestigio de una dinastía, tan dotadas de tesoros - por otra parte - que puedan ser olvidados los no realizados a su tiempo, tan proyectadas sin pasión pero con concupiscencia hacia el futuro, tan desasidas de una auténtica nobleza, tan pobladas de un pueblo achulapado, tan heroicas en ocasiones sin que se sepa a ciencia cierta por qué sino de un modo elemental y físico como el del campesino joven que de un salto cruza el río, tan embriagadas de sí mismas aunque en verdad el licor de que están ahítas no tenga nada de embriagador, tan insospechadamente en otro tiempo prepotentes sobre capitales extranjeras dotadas de dos catedrales y de varias colegiatas mayores y de varios palacios encantados - un palacio encantado al menos para cada siglo_, tan incapaces para hablar su idioma con la recta entonación llana que le dan los pueblos situados hacia el norte a doscientos kilómetros de ella, tan sorprendidas por la llegada de un oro que puede convertirse en piedra pero que tal vez se convierta en carrozas y troncos de caballos con gualdrapas doradas sobre fondo negro, $\tan$ carentes de una auténtica judería, tan llenas de hombres serios cuando son importantes y simpáticos cuando no son importantes, tan vueltas de espalda a toda naturaleza - por lo menos hasta que en otro sitio se inventaron el tren eléctrico y la telesilla-, tan agitadas por tribunales eclesiásticos con relajación al brazo secular, tan poco visitadas por individuos auténticos de la raza nórdica, tan abundantes de torpes teólogos y faltas de excelentes místicos, tan llenas de tonadilleras y de autores de comedias de costumbres, de comedias de enredo, de comedias de capa y espada, de 
comedias de café, de comedias de punto de honor, de comedias de linda tapada, de comedias de bajo coturno, de comedias de salón francés, de comedias del café no de comedia dell'arte, tan abufaradas de autobuses de dos pisos que echan humo cuanto más negro mejor sobre aceras donde va la gente con gabardina los días de sol frío, que no tienen catedral.

Es preciso, ante estas ciudades, suspender el juicio hasta un día. (Omisión)

Hasta que llegue ese día, con el juicio suspendido, nos limitaremos a penetrar en las oscuras tabernas donde asoma sobre las botellas una cabeza de toro disecado con los ojos de vidrio, a pasear hasta muy entrada la madrugada por la calle del Nuncio o de la Bola donde se tropieza con las raíces cortadas de lo que pudo haber sido una ciudad completamente diferente, a contemplar en una plaza grande el rodar ingenuo de los soldados los domingos mientras los pájaros se suicidan uno a uno en el gran vientre vacío del caballo, a seguir los pasos precipitados como si fuera a alguna parte de una mujer pequeña y nerviosa por la noche, a abrazar a los borrachos que dimiten de la realidad, a contemplar la airosa apostura de un guardia cuando pasa una mujer que es más alta que él, a preguntar a un taxista de ojos amarillos de gato de qué modo es posible hacer una estafa en una tienda de paños, a frecuentar una sala de fiestas hasta que el portero gigante de uniforme verde nos conozca y nos deje pensar sin entrada haciéndonos una mueca cariñosa, a gastar la tarde entera en una cafetería sin que la camarera nos sonría una sola vez, a hacer como que bebemos y beber poco, a hacer como que hablamos y no decir nada, a hacer como que vamos al cine yéndonos al cuarto de la pensión con su colcha roja, a visitar el museo de pinturas con una chica inglesa y comprobar que no sabemos dónde está ninguno de los cuadros que ella conoce excepto las Meninas, a inventar un nuevo estilo literario y a propagarlo durante varias noches en un café hasta quedar completamente confundidos, a iniciar amistades que no nos acompañarán hasta la tumba y amores que no nos durarán hasta la noche, a visitar un baile de estudiantes donde las señoritas entran gratis, a calcular cuántas piedras de mechero vende un enano en una esquina, a descubrir cuántos billetes para el metro vende una mujer con un niño de pecho una mañana de invierno, a adivinar cuál es la ley económica que permite que las cerilleras vendan los pitillos uno a uno y con el producto alimenten suficientemente a sus amantes, a pensar cuál sería la idea loca que echó todos los ciegos a la calle hasta en esos días que la nieve cae endurecida y de noche sólo han salido los que iban al estreno, a intentar imaginar cómo - Dios mío- cómo vivía todo este pueblo en los que ellos mismos dicen —ellos sabrán por qué-que fueron los años del hambre. 
Sin duda, lo último que pretendía Juan Benet al escribir una novela era cambiar la sociedad, a diferencia de lo que explícita o implícitamente formaba parte del proyecto literario tanto de Sánchez Ferlosio como de Martín Santos. Para Benet, en palabras que acertadamente subraya Darío Villanueva, el relato, su relato, era ante todo estilo: "oscuros párrafos que sólo entregan su contenido tras repetidas lecturas y sólo se leen realmente si no se han comprendido". Su modelo estilístico es Faulkner y folkneriano es también el territorio en el que transcurren la mayor parte de sus obras, el entorno de Región, equivalente al impronunciable condado folkneriano, escenario predilecto del norteamericano. Y el papel que en Faulkner desempeña la guerra civil americana lo representa en la obra de Benet la Guerra Civil Española. Eso no significa que Benet sea una réplica española de Faulkner; con frecuencia, es mejor, y la relación más correcta que cabe establecer es la existente, por ejemplo, entre el escritor o historiador griego Tucídides y el romano Tácito, no menos admirable el uno que el otro. En cualquier caso y pese a no tener la más mínima pretensión documentalista, Benet es sin duda el escritor que ha logrado una mejor evocación de la Guerra Civil Española entre los muchos -españoles y no españoles - que la han convertido en personal materia narrativa. Oigamos algunos párrafos de "Volverás a Región", novela publicada en 1967, cinco años después que "Tiempo de silencio" y doce, que "El Jarama".

\section{(Cita 3)}

Es cierto, el viajero que saliendo de Región pretende llegar a su sierra siguiendo el antiguo camino real —porque el moderno dejó de serlo- se ve obligado a atravesar un pequeño y elevado desierto que parece interminable.

Un momento u otro conocerá el desaliento al sentir que cada paso hacia adelante no hace sino alejarlo un poco más de aquellas desconocidas montañas. Y un día tendrá que abandonar el propósito y demorar aquella remota decisión de escalar su cima más alta, ese pico calizo con forma de mascarilla que conserva imperturbable su leyenda romántica y su penacho de ventisca. $\mathrm{O}$ bien - tranquilo, sin desesperación, invadido de una suerte de indiferencia que no deja lugar a los reproches- dejará transcurrir su último atardecer, tumbado en la arena de cara al crepúsculo, contemplando cómo en el cielo desnudo esos hermosos, extraños y negros pájaros que han de acabar con él, evolucionan en altos círculos. (Omisión)

El viaje, sin duda, no puede ser más desconsolador: una llanura sin encanto, una meseta pobre y seca cortada al norte por el farallón calizo — donde anidan unas águilas pequeñas como vencejos - que sólo puede coronarse con la cuerda; y por el este un desierto de 
ardiente yeso salpicando de rocas basálticas, descompuestas y afiladas, que al parecer la Sierra ha ido soltando con desgana para distraerse en sus largas y solitarias jornadas a lo largo de siglos y huracanes; tan sólo mitigado por pequeñas charcas de agua milenaria rodeadas de juncos y piornales de malsano aspecto y extensas llanadas cubiertas a lo más de matorral, la jara violenta y silbante y la mata del adviento, de formas leñosas, tenaces y concentradas, habitadas solamente por los pequeños reptiles, esa raza extraña (una estirpe no desesperada, que parece consciente de su próximo extinción) de hermosos, negros, hambrientos y silenciosos pájaros que ya sólo confían en la fosforescencia para su manutención, y una multitud de insectos tan abigarrados de corazas y erizados de armas que siempre parecen dirigirse a Tierra Santa. Cuando al fin - en un aroma inesperado, en el zumbido premonitorio de un insecto o en el susurro de las espadañas (el melancólico canto de su anhelante virginidad y de la lejana gloria del Monje, esa cima con forma de mascarilla que de tanto en tanto envía su soplo desdeñoso y esterilizador) - se adivina la proximidad del bosque prometido, el viajero se encuentra de pronto con un seto de espino, un palo torcido y un letrero semiborrado que le advierte de la antigua prohibición. Cabe pensar que el viajero decidido no se ha de volver con las manos vacías - después de tantos esfuerzos- porque así se le antoje a un aviso anacrónico, colocado allí hace más de cien años, y que se puede echar debajo de un solo puntapié sin que nadie se aperciba de ello. Sin embargo, la realidad debe ser algo distinta porque aun cuando a la gente le consta que un cierto número de personas ha tratado de subir allí, no se sabe de nadie que haya vuelto: se dice que es un país tan salvaje y desierto que sólo quien se prepare a una aventura arriesgada puede concebir esperanzas de llegar a él: porque los farallones infranqueables, los elevados e interminables desiertos donde silba el tártago, los cañones cortados a pico donde cantan los arroyos de montaña bajo el manto de una vegetación lujuriante y hostil (bosques de helecho gigante y fosos infranqueables rellenos de acebo, viburno y hierbabuena) no representan ni con mucho las mayores dificultades de la excursión. En Región apenas se habla de Mantua ni de su extraño guardián: no se habla de él en ninguno de los pueblos de la vega, ni en Región ni en Bocentellas ni en el Puente de Dueña Cautiva ni siquiera en la torre de la iglesia abandonada de El Salvador esas pocas noches - tres o cuatro cada década - en que unos cuantos supervivientes de la comarca (menos de treinta vecinos que no se hablan ni se saludan y que a duras penas se recuerdan, reunidos por un instinto común de supervivencia, exagerado por la soledad, o por un viejo ritual cuyo significado se ha perdido y en el que se representan los misterios de su predestinación) se congregan allí para escuchar el eco de unos disparos que, no se afirma pero se cree, proceden de Mantua. Lo cierto es que nadie se atreve a negar la existencia del hombre, al 
que nadie ha visto pero al que nadie tampoco ha podido llegar a ver y cuya imagen parece presidir y proteger los días de decadencia de esa comarca abandonada y arruinada: un anciano guarda, astuto y cruel, cubierto de lanas crudas como un pastor tártaro y calzado con abarcas de cuero, dotado del don de la ubicuidad dentro de los límites de la propiedad que recorre día y noche con los ojos cerrados.

5

En un ensayo titulado "Dos estilos de comparación: Juan Benet y Luis Goytisolo", Gonzalo Sobejano, profesor de la Universidad de Columbia y académico correspondiente de la RAE, afirma: "El signo prustiano de las comparaciones de Juan Benet y de Luis Goytisolo es evidente: tan evidente como el acento peculiar que cada uno sabe imprimir a este recurso de potenciación imaginativa. Reconociendo el parentesco entre las amplias comparaciones de Goytisolo y las que gustaba hacer Proust, Pere Gimferrer opina, sin embargo, que en vez de cumplir una función de síntesis, de "raccourci", como en "La recherche", se traducen en amplificaciones e insistencias y, en último término, en demoras del ritmo, que constituyen un discurso paralelo al de la narración que corrige a éste y lo remite al área desde la que debemos asumirla, la de la faz oculta de la conciencia".

Yo diría que entre Juan Benet y Luis Goytisolo cabe relacionar a la vez que contraponer no ya la comparación sino el propio estilo. Para Juan Benet el estilo es "una vía independiente de conocimiento, independiente y casi trascendente a ciertas funciones del intelecto que le faculta para una descripción cabal del mundo". Por mi parte, he escrito repetidamente que concibo el relato como un arte total y la creación literaria como una forma de conocimiento superior en la medida en que, a diferencia del pensamiento filosófico, no es rebatible: Homero, Shakespeare, Cervantes, son incuestionables, situados como están por encima de la antítesis verdadero/ falso. Y mi propósito, al escribir, no es el de cambiar la sociedad sino, si acaso, el de cambiar al lector en el sentido de que sea distinto del que era antes de iniciar la lectura, en el sentido de que, al concluirla, sepa algo más no ya acerca del mundo sino sobre todo acerca de sí mismo. Oigamos un fragmento:

\section{(Cita 4)}

9 Sept. La belleza física reside en el cuerpo, pero sólo reside, ya que sólo basta cierto punto su naturaleza es en verdad física. Junto a rasgos propiamente físicos, una determinada armonía de líneas, una determinada calidad de piel, del cabello, de los dientes, hay rasgos que, con todo y manifestarse en el cuerpo, superpuestos a los rasgos físicos, no son de naturaleza física. Su ámbito, más que al cuerpo, pertenece al espíritu, a 
lo que antaño se llamaba el alma, una palabra a la que me parece una lástima haber renunciado, dado su alto valor analógico, cuando lo que con ella se quiere designar es el conjunto de factores síquicos que en el cuerpo tienen su asiento y seguirán teniéndolo hasta que la muerte los separe, todo igual que en una de esas pinturas primitivas que nos muestran el alma inmortal en trance de abandonar la cárcel que para ella fue el cuerpo perecedero, ese cuerpo que ahora exhala, exangüe, su último aliento. Y ello aunque hoy sepamos que las potencias síquicas que constituyen lo que antes se denominaba el alma, así como sus perturbaciones, los soles y lunas de la locura, son mera exteriorización de una oscura cadena de reacciones químicas. En definitiva, cuando te refieres al carácter anímico de tal o cual rasgo físico, todo el mundo te entiende.

Claro que la actitud normal es otra. Cuando la gente alude a la belleza concreta de un cuerpo concreto, no parece sino que lo haga respecto a un todo fragmentable en las diversas partes que lo componen, a un producto susceptible de ser desmontado en elementos de serie: tetas, culo, labios de arriba y de abajo, y ello siempre de acuerdo con un ideal de estandarización establecido de antemano, un ideal que permita clasificarlos en razón de su mayor o menos aproximación al modelo. Para mí, en cambio, está claro que hasta el aspecto de un culo obedece, más que a su propia materialidad, a las órdenes que el cuerpo recibe desde esa área de sombras donde se configura lo que llamamos personalidad.

En un rostro, en su rostro, ¿es la belleza en sí de los ojos lo que manda o es la mirada? ¿La línea estilizada de esos ojos o los pliegues que forman los párpados superiores en su encuentro con los inferiores, rasgos que, así como los meandros de un río son producto no tanto de un capricho del cauce cuanto del fluir del agua, así, de igual modo, no son esos rasgos movimiento fijado, expresión impresa en la materia? ¿Son sus labios o es su sonrisa, o será más bien, como sucede con los ojos, la huella del gesto que conforma la comisura de sus labios lo que da su verdadera peculiaridad a la expresión de su boca? ¿Es acaso obra de un peluquero ese vuelo del pelo que acompaña sus movimientos de cabeza? ¿Cabe afirmar que ese movimiento o vuelo, ese gesto de párpados y de labios, son algo propiamente físico? ¿Serían iguales en ella los cabellos, los ojos y la boca, una vez muerta, con todo y seguir siendo los mismos? ¿No es esa identidad lo primero que desaparece con la muerte, lo que de inmediato convierte a un muerto en un extraño, bruscamente despojado el cuerpo de las manifestaciones visibles de cuanto en él había de invisible?

No es que estuviese a punto de saludarme como se saluda a una persona que se cree conocer y no se sabe de qué. Fue como si nosotros mismos nos presentásemos el uno al otro cuando nuestras miradas se cruzaron y ella desvió la suya. Justamente lo que yo 
sabía que ella iba a hacer, no ya al verla, sino antes de verla, antes de doblar la esquina, pues fue en ese momento, fracciones de segundo antes de tropezarme con ella, cuando supe que iba a tener lugar el encuentro. Descartado un don adivinatorio que no poseo, sólo se me ocurre pensar que tal certidumbre no fue sino el residuo de uno de esos sueños que se interrumpen cuando uno despierta, y que, aunque generalmente luego se olvidan, no por eso dejan de inquietarnos sus atisbos durante el resto del día. Sea como fuere, esto es exactamente lo que sucedió: al doblar la esquina de la calle donde ella y yo vivimos, en la acera de su lado, por la que ahora se iba aproximando con la mirada puesta en los escaparates de una boutique. Y fue al apartar la vista del escaparate cuando su mirada se cruzó con la mía y ella desvió la suya.

Yo seguí caminando sin volverme poseído por una sensación de aturdimiento y extrañeza sólo comparable a la que puede generar una vuelta por la feria de belenes que poco antes de Navidad suele instalarse en los contornos de la catedral, encontrarse de pronto en pleno despliegue de movimiento, sumido en aquel vaho de frescor y rutilancias y villancicos que se expande sobre el área afectada, deambulando entre los tenderetes, entre musgo y muérdago y agujas de abeto, entre olores fugaces, ni sólo a clorofila ni sólo a marihuana, singular atmósfera constituida en base no tanto a lo que es afín y entonado cuanto a lo que resulta chillón y disonante, matracas picassianas, apretujones, floristas con aspecto de campesina soviética, vibrantes víboras de papel, flautas de terracota, las caras del público como flotando sobre un confuso amontonamiento de ropas de abrigo, expresiones ora aleladas, ora perversas, la cómplice fascinación suscitada por la figura del cagador, el brillo codicioso de un diente de oro, y, a modo de réplica de todo aquello, acorde lo pequeño con lo grande, el detalle con la panorámica, a modo de concordancia, la expresión de la señora que tenemos al lado, que contempla lo que nosotros estamos contemplando, una de esas reposadas mujeres de la pequeña burguesía barcelonesa que tanto tienen en común con un repostero de Nuremberg plácida la reposada redondez de su presencia física, de su cara, de sus ojos de pesados párpados, de sus crepados y reteñidos rizos, plácida, sí, aunque no por ello menos jovial y hasta pícara, con ese aire de escuchar la tonadilla de una cajita de música que asume quien, ensimismado, va pensando en las buenas ventas realizadas y en la apacible pipa de porcelana que le aguarda tras la frugal cena solícitamente preparada para ambos por la amada esposa, no bien acabe de cerrar la tienda y todo sea calma en el hogar. Como si más que mercado aquello fuese campamento y la gente allí congregada allí permaneciera en vez de llegar y marcharse, las calles de los alrededores ofrecían un aspecto tranquilo, desahogado, y se diría que hasta los escaparates de los comercios —artesanía, libros de lance, antigüedades - eran una invitación al sosiego. Desde el interior de la tienda, 
poco menos que integrado en la composición de un tapiz flamenco, el anticuario me observaba con aire risueño, casi como si estuviésemos conversando. Y me hallaba yo mirando aún los pequeños objetos expuestos en primer término, contra el cristal, cuando sonó un repiqueteo de campanillas y el anticuario apareció en la puerta. ¿Vendes algo?, me preguntó. Si tú vendes, yo compro.

Una disquisición que inicialmente parece pertenecer a un ensayo pero que pronto se encarna en un relato en primera persona y que, a partir de una comparación relativa al ambiente callejero, continúa en un lugar y un momento distinto a los anteriores. Este fragmento pertenece al comienzo de la última parte de "Antagonía", una extensa novela que escribí entre 1963 y 1979. En ella se narra la vida del protagonista, Raúl, desde sus primeros recuerdos hasta la plasmación de la vocación literaria que, a modo de epifanía, despertó en él su paso por la cárcel, esto es, la elaboración de una novela que constituye la parte final de la obra. ¿Influencias previas? No sabría yo señalar ninguna ni sé de ningún crítico que lo haya hecho, a excepción de la relación con la metáfora proustiana señalada por Gonzalo Sobejano. Y es que, por más que las novelas de Benet y las mías no guarden relación alguna, hay sin duda un referente común que es Marcel Proust.

\section{6}

Para resumir lo dicho hasta ahora, destacaré en primer lugar que, debido a determinadas circunstancias históricas, la novela contemporánea española no empieza a desarrollarse hasta mediados del pasado siglo, concretamente hasta 1955 , fecha de publicación de "El Jarama". Y en segundo lugar, que dicho fenómeno se produce mediante una solución de continuidad conforma a la cual los modelos de la nueva narrativa dejan de pertenecer a la propia tradición, a las obras de sus inmediatos predecesores (Baroja, Galdós, incluso Clarín), y son reemplazados por las obras de determinados novelistas extranjeros como Joyce, Faulkner o Proust. Una situación que ni es nueva en la literatura española — piénsese en la importación del endecasílabo italiano o en los afrancesados del Siglo de las Luces - ni es privativo de España, ya que en un momento $u$ otro se ha producido en todas partes. La influencia de la novela picaresca en Inglaterra (Fielding, Sterne) o del pensamiento inglés en la Francia y los estados alemanes del XVIII.

Lo importante es que el resultado no consiste en un producto mimético, simple traslación de un modelo extranjero, sino una serie de obras originales y genuinamente españolas, capaces de aportar — como si de un injerto se tratara- nueva savia al viejo tronco. Me atrevería incluso a decir que si comparamos algunas de esas novelas 
publicadas a lo largo de la segunda mitad del siglo XX en España con las publicadas en los países de su entorno - Francia, Italia, Alemania - el balance sería muy favorable a la narrativa española aunque por diversos motivos haya sido menos difundida. Claro que también contribuye a ello el vacío creativo que paulatinamente se ha ido extendiendo por esos países y que también ha terminado por alcanzar a España.

Otra cuestión es la influencia ejercida por novelas como las que he reseñado, tanto en España como fuera de ella. "El Jarama" y "Tiempo de silencio" tuvieron inicialmente un gran número de seguidores, pero su influencia ha ido decreciendo hasta esfumarse. En cuanto a las obras de Benet y a las mías, han sido más celebradas que seguidas. A ello habría que referir el vacío creativo antes mencionado y, sobre todo, el triunfo universal en literatura —como en cine, gastronomía o atuendo- del modelo anglosajón de best seller, que acapara un número creciente no ya de lectores sino también de autores.

Pero, dejémonos de lamentaciones. Como hispanistas saben Uds. de sobras que hay que tomarse las cosas con calma y que igual que Uds. exploran desde el presente lo escrito a lo largo de los siglos pasados, también habrá en el futuro quien explore el tiempo presente y lo juzgue. A su juicio me remito. Gracias a todos, por su atención. 